
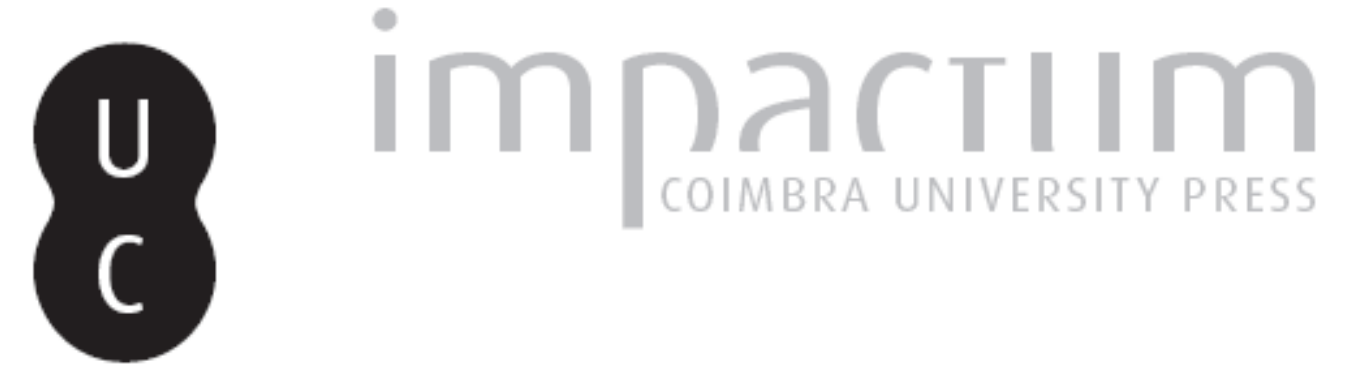

\title{
A Filosofia da religião em David Hume: teísmo, ateísmo ou deísmo?
}

\section{Autor(es): Dimas, Samuel}
Publicado por: Faculdade de Letras da Universidade de Coimbra, Instituto de Estudos Filosóficos

URL
persistente: $\quad$ URI:http://hdl.handle.net/10316.2/35588

DOI: ～DOI:http://dx.doi.org/10.14195/0872-0851_46_9

Accessed : $\quad$ 26-Apr-2023 11:52:41

A navegação consulta e descarregamento dos títulos inseridos nas Bibliotecas Digitais UC Digitalis, UC Pombalina e UC Impactum, pressupõem a aceitação plena e sem reservas dos Termos e Condições de Uso destas Bibliotecas Digitais, disponíveis em https://digitalis.uc.pt/pt-pt/termos.

Conforme exposto nos referidos Termos e Condições de Uso, o descarregamento de títulos de acesso restrito requer uma licença válida de autorização devendo o utilizador aceder ao(s) documento(s) a partir de um endereço de IP da instituição detentora da supramencionada licença.

Ao utilizador é apenas permitido o descarregamento para uso pessoal, pelo que o emprego do(s) título(s) descarregado(s) para outro fim, designadamente comercial, carece de autorização do respetivo autor ou editor da obra.

Na medida em que todas as obras da UC Digitalis se encontram protegidas pelo Código do Direito de Autor e Direitos Conexos e demais legislação aplicável, toda a cópia, parcial ou total, deste documento, nos casos em que é legalmente admitida, deverá conter ou fazer-se acompanhar por este aviso.

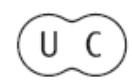




\section{REVISTA FILOSÓFICA DE COIMBRA}

vol. 23 - número 46 - outubro 2014

vol. 23 - número 46 - outubro 2014

Fundação Eng. António de Almeida

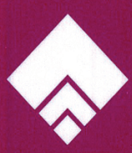




\title{
A FILOSOFIA DA RELIGIÃO EM DAVID HUME: TEÍSMO, ATEÍSMO OU DEÍSMO?
}

\author{
SAMUEL DIMAS*
}

Resumo: Na sua filosofia da religião, David Hume faz a distinção entre teísmo genuíno, que corresponde à afirmação de que toda a estrutura da natureza indica um Ser Supremo, autor inteligente e criador da ordem do Mundo, e teísmo supersticioso, que corresponde à crença do politeísmo idólatra na ação servil e familiar dos poderes superiores, descritos de forma antropomórfica com paixões e apetites, membros e órgãos humanos.

A partir desta distinção procuraremos mostrar que na obra deste autor não está em causa a essencial verdade religiosa acerca da existência de Deus, que surge à razão como óbvia, mas sim a conceção antropomórfica dos atributos divinos e a sua adequada cognoscibilidade, bem como a forma das religiões conceberem a relação providencial com as criaturas no sentido da suprema justiça e da instauração de um futuro perfeito de integral redenção. Só é possível afirmar da causa divina aquilo que se pode inferir da experiência que fazemos dos seus efeitos

Assim, consideraremos que a sua posição não é de ateísmo, no sentido etimológico do termo, mas sim de deísmo, no sentido de se inferir racionalmente a partir dos efeitos a existência da Divindade, como causa última de toda a ordem natural, sem, no entanto, ser possível a compreensão filosófica da sua incomensurável essencialidade, ficando o seu obscuro e contraditório discurso remetido para o plano da fé.

Palavras Chave: teísmo puro, teísmo supersticioso, ateísmo, deísmo, criação, politeísmo, Providência original, providência particular, antropomorfização, religião filosófica, Deus.

* Centro de Estudos de Filosofia da Faculdade de Ciências Humanas da Universidade Católica Portuguesa; sdimas@fch.lisboa.ucp.pt. 
Summary: In his philosophy of religion, David Hume makes the distinction between genuine theism, that corresponds to the affirmation that the entire structure of nature indicates a Supreme Being, an intelligent designer and creator of order in the world, and superstitious theism, that corresponds to the belief in idolatrous polytheism based on the servile and familiar actions of superior powers described in an anthropomorphic form, with human passions and appetites, members and organs.

From this distinction, we aim to demonstrate that the work of this author does not put at stake the essential religious truth in what concerns as regards the existence of God, which emerges to reason as obvious, but instead questions the anthropomorphic conception of divine attributes and its cognoscible appropriateness as well as the way in which religions conceive their providential relationship with their creatures on the scope of supreme justice and the enactment of a perfect future of integral redemption. It is only possible to affirm the divine cause from inferences o that are taken out from the experience that we make of its effects.

Hence, we do not consider that his position falls under the auspices of atheism, in the etymologic meaning of the term, but rather represents deism in the sense of rationally inferring based upon the effects of a Divinity existence as the ultimate cause for the entire extent of the natural order, without which it's impossible a philosophical comprehension of its incommensurable essentiality leaving to obscure and contradictory discourse to the domain of faith.

Keywords: pure theism, superstitious theism, atheism, deism, creation, polytheism, original providence, particular providence, anthropomorphisation, philosophy of religion, God.

\section{O teísmo genuíno e finalista da religião filosófica}

A releitura mais atenta da obra História Natural da Religião de David Hume fez-nos voltar a refletir sobre a seguinte questão: deveremos falar de teísmo ou ateísmo na filosofia da religião deste autor?

Para respondermos a esta interrogação fomos investigar os vários textos em que o autor apresenta as suas reflexões sobre filosofia da religião e iniciámos pelas seguintes obras: Os Diálogos sobre Religião Natural, que começaram a ser escritos em 1750 e que foram revistos pela última vez em 1776, no ano da sua morte, vindo a ser publicados postumamente em 1779; e História Natural da Religião, publicada em 1757.

Esta última obra, que pretende ser um estudo científico sobre o fenómeno humano da religiosidade, encerra uma profunda crítica às religiões populares politeístas e às religiões reveladas, por contraposição com o teísmo finalista da religião filosófica, que defende racionalmente a origem divina da ordem natural. Assim, logo na introdução, o autor, por contraposição com as posi- 
ções incrédulas ou cépticas, faz uma distinção entre o teísmo puro ou genuíno e o teísmo supersticioso.

Ao teísmo genuíno corresponde a afirmação de que toda a estrutura da natureza indica um autor inteligente e criador da ordem do Mundo, em que tudo está ajustado a tudo de acordo com um único desígnio ou plano que prevalece com uniformidade na totalidade das coisas ${ }^{1}$. Raciocinando a partir das estruturas da natureza com curiosidade especulativa e puro amor à verdade, o homem é conduzido à crença num Ser Supremo e não à crença no politeís$\mathrm{mo}^{2}$. No seu entender, nenhuma reflexão racional séria pode suspender a sua adesão aos primeiros princípios do teísmo genuíno ${ }^{3}$.

Ao teísmo supersticioso corresponde, não apenas a crença do politeísmo idólatra na ação servil e familiar dos poderes superiores, descritos de forma antropomórfica com paixões e apetites, membros e órgãos humanos ${ }^{4}$, mas também a crença do monoteísmo num Deus, puro espírito, com poderes perfeitos de omnipotência e omnipresença e com atributos morais ${ }^{5}$. No caso deste teísmo, que se transmite historicamente por narrações sucessivas em vez de se constituir pelo raciocínio e por uma argumentação clara e óbvia, a origem das ideias religiosas reside na natureza humana ${ }^{6}$, nos seus medos e esperanças, sendo essa a mesma origem da crença de que a natureza está cheia de poderes invisíveis como fadas e gnomos ${ }^{7}$.

Considera David Hume que a diferença entre este segundo teísmo e o ateísmo de quem exclui em absoluto a existência de qualquer poder invisível e inteligente é muito menor que em relação ao teísmo genuíno que recusa as representações antropomórficas ${ }^{8}$. Em vez de reconhecer a harmonia e beleza do mundo natural como obra de um ser divino superior, criador e omnipotente ${ }^{9}$, o politeísta deifica todas as partes do Universo e concebe todas as conexões da natureza como verdadeiras divindades ${ }^{10}$.

Face ao descrito logo no início da obra História Natural da Religião, podemos chegar a uma primeira conclusão. Por um lado, David Hume não nega a essencial verdade religiosa acerca da existência de Deus, mas, por outro

${ }^{1}$ Cf. David Hume, Natural History of Religion, sect. II, in The Philosophical Works, edited by Thomas Hill Green and Thomas Hodge Grose, volume 4, London, Scientia Verlag Aalen, 1964, p. 314.

2 Cf. ibidem, sect. I, p. 312.

3 Cf. ibidem, introduction, p. 309.

${ }^{4}$ Cf. ibidem, sect. I, p. 311.

5 Cf. loc. cit.

${ }^{6}$ Cf. ibidem, introduction, p. 309.

7 Cf. ibidem, sect. IV, p. 320.

8 Cf. ibidem, sect. IV, pp. 320-321.

9 Cf. ibidem, sect. VI, p. 328.

10 Cf. ibidem, sect. V, p. 325. 
lado, e paradoxalmente, o seu teísmo recusa os elementos religiosos no mesmo sentido em que o fazem as posições que habitualmente caracterizamos de ateístas, como por exemplo: a recusa da cognoscibilidade dos atributos morais divinos; a recusa da conceção personalista de Deus e do seu carácter transcendente, reduzindo-o um princípio absoluto imanente à História e ao Mundo; a recusa da possibilidade da Revelação e da relação de Deus com os homens através da Graça e a recusa da Ressurreição para um estado futuro de perfeita e eterna felicidade.

Sob o ponto de vista etimológico o termo teísmo vem do grego $\theta \varepsilon o ́ s$ (que quer dizer Deus) e à semelhança do termo deísmo, que vem do latim deus, significa «crença em Deus» ou «doutrina que admite a crença na existência de Deus», pelo que, neste sentido, podemos dizer que David Hume não é ateu. Sublinhe-se que na sua obra Investigação sobre o Entendimento Humano, publicada em 1748, David Hume afirma que a ideia de Deus como um Ser infinitamente inteligente e bondoso apenas deriva das operações da nossa mente, elevando ao limite, de forma antropomórfica, as qualidades humanas de bondade e sabedoria ${ }^{11}$. Assim, considera que o alegado poder criador e omnipotente do Ser infinito, como causa imediata dos acontecimentos e fenómenos naturais, não pode ser sentido, nem conhecido, nem concebido pelo espírito humano ${ }^{12}$. Mas apesar destas posições, o autor não nega a existência do Ser supremo como causa última e original de todas as coisas. O que Hume nega é que os fenómenos, os acontecimentos, as ações e as vontades sejam efeito imediato da volição ou providência particular desse Ser supremo ${ }^{13}$.

\section{A Providência original das leis gerais e imutáveis que regem a ordem da criação}

Nesse sentido, como explicitará na obra História Natural da Religião, o autor faz a distinção entre a Providência original e a providência particular: a primeira, por ele aceite, refere-se às leis gerais e imutáveis, que regem a ordem ou o desígnio da Criação; a segunda, por ele rejeitada, refere-se aos acontecimentos e às ações humanas como efeito imediato e arbitrário das volições particulares da inteligência divina. Na obra Diálogos sobre a

${ }^{11}$ Cf. idem, An Enquiry Concerning Human Understanding, sect. II, n. ${ }^{\circ} 14$, in Enquiries Concerning Human Understanding and Concerning the Principles of Morals, edited with introduction, comparative table of contents, and analytical índex by L. A. Selby-Bigge, third edition with text revised and notes by P.H. Nidditch, London, Oxford University Press, 1982, p. 19.

12 Cf. ibidem, sect. VII, part. I, n. ${ }^{\circ}$ 53-54, pp. 67-69.

13 Cf. ibidem, sect.VII, part. I, n. ${ }^{\circ}$ 54-55, pp. 69-70. 
Religião Natural, esta crítica é colocada na voz de Filon, que a partir da aparência das coisas diz não se poder inferir a bondade dos poderes superiores, acrescentando que se tudo fosse conduzido por um Ser infinitamente bom e benevolente através de volições particulares, o curso da natureza não seria regular e todos os acidentes da realidade do mal natural e do mal moral poderiam ser alterados no sentido do bem, tornando a humanidade plenamente feliz ${ }^{14}$. Por outro lado, considera que se houver razões para a providência não ter interferido desta maneira, não poderão ser conhecidas por nós ${ }^{15}$, porque a partir da experiência do mundo temos todos os motivos para excluir da Divindade os sentimentos morais, nos mesmos termos em que nós os sentimos (antropomorfização) ${ }^{16}$.

$\mathrm{O}$ autor sublinha que ignoramos completamente a forma como o Espírito ou Ser Supremo opera sobre si e sobre os corpos, isto é, não podemos ter qualquer ideia dessa energia, desse poder ou conexão necessária, porque é uma coisa que nunca se apresentou aos nossos sentidos internos ou externos ${ }^{17}$. A nossa ideia de necessidade e causação ou conexão entre objetos apenas deriva da habitual observação acerca da uniformidade das operações da natureza e da conjugação regular dos seus objetos, nada se podendo dizer acerca de questões como a origem dos mundos e o reino dos espíritos ${ }^{18}$ ou de questões como a conexão entre a causa última do Ser Supremo e o efeito dos seres. Tudo o que sentimos reduz-se ao evento ou efeito ${ }^{19}$, pelo que a natureza do Ser Divino é totalmente incompreensível ${ }^{20}$. Neste sentido, reafirma David Hume na sua Investigação sobre o Entendimento Humano, que não é possível à razão natural explicar a conciliação entre a perfeição e bondade atribuídas à causa original da Divindade - como autoria última das nossas volições - e a imperfeição e maldade das nossas ações morais, sem reconhecer nessa mesma Divindade a autoria última do pecado moral de todas as suas criaturas ${ }^{21}$.

14 Cf. idem, Dialogues Concerning Natural Religion, part. XI, in The Philosophical Works, edited by Thomas Hill Green and Thomas Hodge Grose, volume 2, London, Scientia Verlag Aalen, 1964, pp. 447-448.

15 Cf. loc. cit.

16 Cf. ibidem, part. XI, p. 453.

17 Cf. idem, An Enquiry Concerning Human Understanding, sect. VII, part. II, n. ${ }^{\circ}$ 58, in Enquiries Concerning Human Understanding and Concerning the Principles of Morals, pp. 73-74.

18 Cf. ibidem, sect. VII, part. I, n. ${ }^{\circ} 48-49$, pp. 60-62.

19 Cf. ibidem, sect. VII, part. I, n. ${ }^{\circ}$ 53, pp. 67-68.

20 Cf. idem, Dialogues Concerning Natural Religion, part. XI, in The Philosophical Works, volume 2, p.453.

21 Cf. idem, An Enquiry Concerning Human Understanding, sect. VIII, part. II, n. ${ }^{\circ} 78-81$, in Enquiries Concerning Human Understanding and Concerning the Principles of Morals, pp. 99-103. 
Mas também esta conclusão não o leva a negar essa Divindade, mas sim a reconhecer que a consideração da sua relação com as criaturas se situa num âmbito misterioso, cheio de dúvidas, incertezas e contradições, que excede o poder da reflexão filosófica ${ }^{22}$. Esta posição de David Hume acerca do carácter ininteligível e misterioso da Divindade será defendida na obra $\mathrm{Os} \mathrm{Di}$ álogos sobre Religião Natural pelas posições mística de Demea e céptica de Filon que, de forma análoga, defendem a incapacidade da limitada inteligência humana em conhecer de forma adequada a natureza da Causa Suprema do Universo, porque não tem experiência das suas operações divinas.

Estas posições parecem evidenciar um fideísmo implícito, no sentido em que Hume afirma ser impossível conhecer os atributos ou ações do Ser Supremo, a não ser pela experiência que temos das suas operações no curso comum da natureza ${ }^{23}$, remetendo as questões religiosas da providência redentora e do estado futuro da justiça divina para o plano da fé24. Uma tese que é representada na obra dos Diálogos sobre a Religião Natural na crítica que o teísta Cleanto faz a Filon por este sustentar a fé religiosa no ceticismo filosófico, promovendo a cisão entre fé e razão e remetendo o conhecimento e a reflexão acerca do Ser divino para o plano das doutrinas teológicas ${ }^{25}$. Esta contraposição surge de forma bem explícita na análise que o autor faz ao problema dos milagres, quando defende que os pressupostos da religião cristã assentam na fé da revelação bíblica e não na razão, sendo inconcebível submetê-la a demonstrações e provas que não pode $\operatorname{suportar}^{26}$.

\section{A impossibilidade de atribuir à causa última qualidades que exce- dem o que aparece nos efeitos secundários}

Inserindo-se nas correntes da dupla verdade da filosofia e da teologia, ou da justaposição entre as ordens da razão e da fé, o pensamento deste autor apresenta a verdade revelada, não em relação de cumplicidade e de complementaridade com a verdade racional, mas sim, como sublinha Filon, na última parte dos Diálogos, em alternativa segura à total ignorância da razão natural

22 Cf. ibidem, sect. VIII, part. II, p. 103.

23 Cf. ibidem, sect. X, part. II, n. ${ }^{\circ}$ 99, p.129.

${ }^{24}$ Cf. ibidem, sect. X, part. II, n. ${ }^{\circ} 100$, p. 130.

25 Cf. idem, Dialogues Concerning Natural Religion, part. I, in The Philosophical Works, volume 2, p. 382.

26 Cf. idem, An Enquiry Concerning Human Understanding, sect. X, part. II, n. ${ }^{\circ}$ 100, in Enquiries Concerning Human Understanding and Concerning the Principles of Morals, p. 130. 
acerca dos assuntos divinos ${ }^{27}$. Numa primeira leitura, esta posição poderá levar a concluir que o projeto de David Hume acerca da verdade da religião natural é inviável, porque racionalmente indemonstrável, constituindo-se a religião revelada como a verdadeira religião (teísmo fideísta).

Para o autor escocês as verdades religiosas acerca da existência de Deus com atributos morais e acerca da imortalidade da alma ou da redenção do mundo não se podem demonstrar nem negar pela razão, apenas sendo possível afirmar como plausível e provável aquilo que deriva da observação da ordem fenoménica do mundo. Por isso, julgamos que se pode concluir que a reflexão de David Hume encerra uma perspetiva teísta, mas apenas no seu sentido etimológico originário de alcance mais abrangente, colocando o ceticismo filosófico como condição para aceder à verdade religiosa. Como defende Álvaro Nunes a este propósito, a preocupação de David Hume não é justificar o ateísmo, mas tão só tornar evidentes as dificuldades do teísmo (ceticismo), mostrando que os principais dogmas da religião não têm fundamento racional ${ }^{28}$.

Mas historicamente o termo teísmo foi sendo usado num sentido mais restrito, que exclui não apenas o politeísmo e o panteísmo, mas também o deísmo, pela afirmação da cognoscibilidade dos atributos de Deus único e da sua ação providencial nos acontecimentos da vida humana através de uma intervenção sobrenatural, que para além da Revelação e da Graça do Espírito Santo, pode incluir também os milagres, as experiências místicas e a crença no mistério da Ressurreição para a vida eterna da Glória de Deus. Neste caso, pelo que lemos da sua religião natural, teremos de dizer que David Hume é um ateu. Na secção XI da sua Investigação sobre o Entendimento Humano, embora o autor comece por afirmar que nunca pôs em dúvida a existência divina $^{29}$, afirma que o argumento em favor desta apenas deriva da ordem da natureza e que deste efeito não se pode inferir uma causa com qualidades adicionais ou capaz de produzir outros efeitos que não sejam aqueles que nós conhecemos pela experiência ${ }^{30}$. A dotação de atributos e princípios de ação, cuja realização não podemos verificar, apenas pode ficar para o campo conjetural da mera hipótese ou possibilidade.

A partir da existência da ordem do Universo podemos inferir que o seu autor Supremo possui o grau de poder, inteligência e benevolência que se

27 Cf. idem, Dialogues Concerning Natural Religion, part. XII, in The Philosophical Works, volume 2, p. 467.

28 Cf. Álvaro Nunes, «Introdução», in Diálogos Sobre a Religião Natural, Lisboa, Edições 70, 2005, p. XLII.

29 Cf. David Hume, An Enquiry Concerning Human Understanding, sect. XI, n. ${ }^{\circ}$ 104, in Enquiries Concerning Human Understanding and Concerning the Principles of Morals, p. 135.

30 Cf. loc. cit. 
manifesta na sua obra, mas não podemos inferir atributos que não sejam proporcionais à sua manifestação, isto é, não podemos inferir que esse autor não possa deixar de produzir algo maior e mais perfeito do que a existência catual das coisas repleta de males e de desordens ${ }^{31}$. De acordo com esta perspetiva, o estado futuro do Paraíso Celestial que atribuímos à ação de uma inteligência e benevolência superlativa é apenas fruto da imaginação, não tendo qualquer fundamento na razão: não podemos aceitar antecipadamente tais atributos, conferindo à Causa última qualidades que estão para além daquilo que efetivamente aparecem no efeito ${ }^{32}$.

Como sublinha no ensaio da imortalidade da alma, por aquilo que a razão natural julgar, a finalidade e intenção no projeto da criação dos seres humanos está limitada a esta vida, não sendo possível demonstrar que Deus possui mais atributos que aqueles que correspondem à ação exercida no Universo conhecido pelo homem ${ }^{33}$. Assim David Hume recusa o teísmo ou a crença numa providência divina de suprema justiça, que guie o curso dos acontecimentos, castigando os maus com a desilusão e recompensando os bons com o sucesso, mas não nega o próprio curso dos acontecimentos, nem nega de forma definitiva a causa divina dos $\operatorname{mesmos}^{34}$.

\section{A afirmação deísta da existência de um Ser supremo criador que só por conjetura pode ter uma ação sobrenatural no mundo}

Perante estas conclusões, parece legítima a hermenêutica mais recente da obra de David Hume, de autores como J.C.A.Gaskin, na afirmação de que as suas rotulagens de ateísmo absoluto, ceticismo e agnosticismo são enganosas, porque não conseguem identificar corretamente a distinção operada por Hume entre teísmo genuíno e teísmo supersticioso, nem o alcance da sua crítica ao politeísmo idolátrico e ao dogmatismo religioso do monoteísmo. A posição intelectual de David Hume em relação à religião não é de neutralidade, mas de crítica profunda e, por isso, também não nos parece que o termo que melhor caracteriza a sua atitude seja o de irreligião, porque é óbvia a sua profusa reflexão sobre as formas de religião natural e religião revelada, apenas superada pela quantidade de textos de carácter histórico ${ }^{35}$.

31 Cf. ibidem, sect. XI, n. ${ }^{\circ} 106$, p. 137.

32 Cf. ibidem, sect. XI, n. ${ }^{\circ} 107$, p. 139.

${ }^{33}$ Cf. idem, Unpublished Essays, essay I, in The Philosophical Works, edited by Thomas Hill Green and Thomas Hodge Grose, volume 4, London, Scientia Verlag Aalen, 1964, p. 400.

34 Cf. idem, An Enquiry Concerning Human Understanding, sect. XI, n. ${ }^{\circ}$ 108, in Enquiries Concerning Human Understanding and Concerning the Principles of Morals, p.140.

35 J.C.A.Gaskin, Hume's Philosophy of Religion, London, Macmillan, 1988, p.1. 
Em consonância com a posição de J.C.A.Gaskin que não tem dúvida em afirmar que a crítica de David Hume à religião não significa a descrença em Deus, e, na identificação do seu sentimento do desígnio e da sua justificação racional de um agente para a obra da ordem da natureza, lhe atribuí a posição de «deísmo atenuado» ${ }^{36}$, assim também nos parece que o termo deísmo é o mais acertado para caracterizar a posição religiosa de David Hume. É aquele que mais se identifica com a sua noção de teísmo genuíno, no sentido de admitir a noção de um Deus, ou Primeira Causa, que criou o mundo e as leis imutáveis que o regem. Na sua elaboração definitiva, o termo deísmo afirma a existência de um Ser supremo criador do mundo, mas nega a sua intervenção sobrenatural ulterior à criação. Também João Paulo Monteiro, na sua introdução ao livro sobre as obras de religião de David Hume, editado pela Gulbenkian, embora não tome uma posição explícita e queira deixar para o leitor a decisão acerca de uma posição agnóstica ou deísta, afirma não conhecer ninguém que veja hoje em David Hume um ateu e que são poucos que, à semelhança de James Noxon, o vêm como agnóstico ${ }^{37}$, considerando, assim, como plausível que lhe seja atribuída a posição religiosa de deísmo ${ }^{38}$.

De certa maneira, podemos dizer que é neste sentido que, por exemplo, Kant apresenta a distinção entre deísmo, que caracteriza a posição de quem só admite um conhecimento do Ser originário por via da razão pura, mediante conceitos meramente transcendentais (teologia transcendental), e teísmo, que caracteriza a posição de quem também admite o conhecimento da existência de um ser primeiro por via de um conceito que deriva da natureza da nossa alma (teologia natural). No primeiro caso, o nosso conceito é o de um ser primeiro que possui toda a realidade, mas que não se pode determinar de forma mais precisa; no segundo caso, admite-se que a razão é capaz de determinar o seu objeto com mais precisão, pela analogia com a natureza, ou seja, determiná-lo como um ser que, pelo entendimento e pela liberdade, contém em si a razão primeira de todas as outras coisas, constituindo-se não apenas como causa, mas também como autor do mundo ${ }^{39}$, não apenas como Ser supremo, mas como Deus vivo ${ }^{40}$.

Na perspetiva de David Hume, mesmo concedendo que Deus é o autor da existência e da ordem do Universo, daí apenas se pode inferir e provar que possui o grau de poder, inteligência e benevolência, que se manifesta na sua obra, ficando a suposição de atributos adicionais e de plenificação de

36 Cf. ibidem, p. 221.

37 Cf. João Paulo Monteiro, «Introdução», in Obras sobre Religião, Lisboa, Fundação Calouste Gulbenkian, 2005, p. XVI.

38 Cf. ibidem, p. XV.

39 Cf. Immanuel Kant, $K r V$, A 631 - A 632.

40 Cf. ibidem, A633. 
atributos morais reduzida a uma mera hipótese ${ }^{41}$. Conhecer Deus mais não significa que saber que ele existe e que criou a ordem visível da natureza através de leis invariáveis ${ }^{42}$. O Deus do deísmo filosófico é o Deus do mecanicismo racionalista, em que o mundo criado nos surge como uma máquina perfeita com as suas leis fixas e imutáveis, que lhe garantem a ordem e a harmonia, ou como um animal ou corpo organizado em que a divindade é a sua alma como princípio de vida e movimento ${ }^{43}$. A Providência original de que nos fala o autor é a da criação dessas leis e dessa organização imutável e eterna e não a de uma ulterior intervenção, seja ela milagrosa ou revelacional e escatológica, tal como é apresentada pelo carácter redentor das religiões.

Mas pelo facto de Hume admitir a probabilidade de a causa da ordem do Universo ter apenas uma remota analogia com a inteligência humana e pelo facto de afirmar a misteriosa e incompreensível natureza da divindade ${ }^{44}$ e do todo $^{45}$, leva-nos também a concluir que o teísmo genuíno nos deixa numa profunda ignorância, constituindo-se como uma hipótese teoricamente vazia e praticamente inútil, digna de um profundo ateísmo no sentido estrito do termo. Esta parece ser a conclusão do próprio autor, quando no fim da última secção da sua História Natural da Religião afirma que o todo é um enigma ou um inexplicável mistério, pelo que a dúvida e a suspensão do juízo parecem ser o único resultado do escrutínio mais rigoroso sobre o fundamento da realidade ${ }^{46}$.

Neste sentido também se compreende a posição do teísmo tradicional em pôr em evidência o quão é difícil chegar, apenas pela razão, a um correto e seguro conhecimento de Deus. Esta hesitação acerca da afirmação do Princípio Criador também parece na secção XI da Investigação sobre o Entendimento Humano, quando David Hume afirma, não só que a conceção desta vida como uma passagem para algo mais além é um produto da fantasia e da imaginação, mas também quando afirma que o raciocínio a partir do curso da natureza, que permite inferir uma causa inteligente que originalmente imprimiu uma ordem ao Universo e continuamente a preserva, é um raciocínio que significa adotar um princípio tão incerto quanto inútil, porque se trata de

41 Cf. David Hume, An Enquiry Concerning Human Understanding, sect. XI, n. ${ }^{\circ}$ 106, in Enquiries Concerning Human Understanding and Concerning the Principles of Morals, p. 137.

42 Cf. idem, Natural History of Religion, sect. XV, in The Philosophical Works, volume 4 , p. 362.

43 Cf. idem, Dialogues Concerning Natural Religion, part. VI, in The Philosophical Works, volume 2, p. 416.

44 Cf. ibidem, part. IV, p. 405.

45 Cf. idem, Natural History of Religion, sect. XV, in The Philosophical Works, volume 4, p. 363.

46 Cf. loc. cit. 
algo completamente fora do alcance da experiência e porque, derivando o conhecimento dessa causa do curso da natureza de acordo com as regras do raciocínio, não é possível voltar a partir da causa para novas inferências ${ }^{47}$.

Só podemos conhecer a Divindade a partir das suas produções, pelo que tudo o que for acrescido às obras da natureza, produzindo um acréscimo no Autor dessa natureza, já não tem apoio na argumentação racional e apenas poderá ser admitido no plano da mera conjetura e hipótese ${ }^{48}$. O Ser de Deus é remoto e incompreensível, revelando-se apenas por ténues indícios e vestígios, para além dos quais não podemos conferir atributos de maior perfeição, a não ser através de formas de adulação ${ }^{49}$.

\section{O Ser supremo é ininteligível e a descrição racional do seu poder não pode exceder o que é observável pelos efeitos do mundo natural}

Esta posição será posta em evidência e radicalizada na obra dos Diálogos, estilo literário que o autor escolhe pelo facto de lhe parecer o mais adequado para tratar das questões filosóficas obscuras e incertas a que a razão humana não pode dar uma resolução fixa e definitiva ${ }^{50}$. A própria analogia e proporção entre o efeito e a causa parece ser posta em dúvida. Contra o teísmo de Cleanto, que defende a perspetiva finalista, nomeadamente o argumento do desígnio, segundo o qual existiria uma finalidade na natureza, introduzida por Deus, e o mundo ordenado seria um projeto do Criador, constituindo-se como a prova mais importante da sua existência, a posição céptica de Filon defende que nada nos garante que o princípio original de ordem e organização que há na mente humana possa ser transposto de forma analógica ou semelhante para uma mente divina: essa possível semelhança entre a Divindade e as criaturas humanas é concebida por Filon como uma degradação do Ser supremo e, por isso, concorda com Demea quanto ao carácter misterioso da natureza divina ${ }^{51}$.

Considera Filon que, devido à grande desproporção que há entre a parte e o todo, o desígnio e a inteligência, que identificamos na arte humana, não podem ser atribuídos à origem do todo ou à causa original de todas as coisas,

${ }^{47}$ Cf. idem, An Enquiry Concerning Human Understanding, sect. XI, n. ${ }^{\circ} 110$, in Enquiries Concerning Human Understanding and Concerning the Principles of Morals, p.142.

48 Cf. ibidem, sect. XI, n. ${ }^{\circ} 113$, pp. 144-145.

49 Cf. ibidem, sect. XI, n. ${ }^{\circ} 113$, p. 145-146.

50 Cf. idem, Dialogues Concerning Natural Religion, Pamphilus to Hermippus, in The Philosophical Works, volume 2, p. 378.

51 Cf. ibidem, part. II, pp. 395-396. 
porque disso não temos experiência ${ }^{52}$. Considerando que uma ínfima parte não pode constituir uma regra para o Universo, Filon defende que não é possível apresentar uma definição ou descrição da Divindade e não é possível provar a origem do Universo a partir da mente de Deus, porque, ao contrário daquilo que defende Cleanto, não é possível provar a similaridade dos trabalhos da natureza com os da $\operatorname{arte}^{53}$. Mas pelo que conhecemos da sua obra, David Hume não se identifica totalmente com esta posição de Filon defendida nas primeiras onze partes dos Diálogos. Por exemplo, na História Natural da Religião é rejeitada a providência particular ${ }^{54}$, associada à divindade tutelar de cada nação, mas não é negada a Providência original da mente suprema ${ }^{55}$, isto é, o plano ou desígnio fixado nas leis gerais que governam a ordem natural do Universo ${ }^{56}$.

Esta regularidade ou uniformidade das leis da natureza é concebida por David Hume como a prova mais forte de desígnio e de uma inteligência suprema ${ }^{57}$. Perante o anteriormente descrito, e em contraposição com a tendência generalizada em associar o pensamento do autor ao pensamento de Filon, poderíamos ser tentados a substituir essa identificação. Por que não associar o pensamento de David com o de Hérmipo, leitor e ouvinte de Pânfilo, ou com o pensamento do próprio Pânfilo, que na introdução da obra explica a importância de descrever o diálogo entre o rigoroso espírito filosófico de Cleanto, o ceticismo descuidado de Filon e a inflexível ortodoxia de Demea, que na última frase dos Diálogos afirma que o pensamento teísta e finalista de Cleanto está mais próximo da verdade que o pensamento cético de Filon ${ }^{58}$ ? Julgamos que qualquer das posições é incorreta e devemos evitar a tendência de procurar descobrir em que autor dos Diálogos se esconde o próprio David Hume, pois o seu pensamento distingue-se, não apenas de Filon, mas também de Cleanto.

Por outro lado, independentemente das razões objetivas para tal facto, o pensamento de Filon não é o mesmo ao longo de toda a obra. Repare-se que na parte XII dos Diálogos, Filon passa de uma argumentação cética, que nega o desígnio da Criação e nega a atribuição dos atributos humanos à Divindade, para uma posição que descreve a Causa Suprema como mente ou

52 Cf. ibidem, part. II, p. 397.

53 Cf. ibidem, part. III, p. 400.

54 Cf. idem, Natural History of Religion, sect. VI, in The Philosophical Works, volume 4, p. 329.

55 Cf. ibidem, sect. VIII, p. 334.

56 Cf. ibidem, sect. II, p. 315; sect. VI, p. 329.

57 Cf. ibidem, sect. VI, p. 330.

58 Cf. idem, Dialogues Concerning Natural Religion, part. XII, in The Philosophical Works, volume 2, p. 468. 
pensamento e com um grau de poder e energia desproporcionalmente superior aos efeitos que observamos na humanidade ${ }^{59}$. Ora, acontece que, quer uma posição, quer outra, contrariam a argumentação que David Hume vai desenvolvendo na sua Investigação sobre o Entendimento Humano: por um lado, Hume nesta obra nunca nega a Divindade como Causa criadora do Universo e, por outro lado, nela sempre afirma que o Ser Supremo é ininteligível e a descrição racional do seu poder não pode ir além daquilo que observamos pelos efeitos do mundo natural. O que aliás se assemelha ao afirmado por Filon na parte II em que apresenta a impossibilidade da definição e descrição de Deus, porque é uma realidade tão sublime e distante da nossa observação, que a razão acerca dela se enreda em frágeis e contraditórias conjeturas ${ }^{60}$, não sendo possível inferir uma conclusão das partes para o todo, devido à radical desproporção existentes entre eles.

Ao contrário do que defende o teísmo de Cleanto, David Hume partilha com as perspetivas de Filon e Demea, a noção de que não podemos ter uma adequada compreensão dos atributos divinos ${ }^{61}$, porque estes não têm semelhança com as qualidades dos homens e as ideias dos homens não correspondem às perfeições divinas, que são infinitamente superiores ${ }^{62}$. A natureza do ser supremo é misteriosa e incompreensível, não podendo ser explicada pelo raciocínio ou pelo discurso inteligível ${ }^{63}$. Noutro sentido, embora por um lado, ao contrário de Fílon, não negue o mundo como fruto de um plano da mente de Deus, por outro lado, á semelhança de Filon, critica o antropomorfismo defendido pela posição representada por Cleanto ${ }^{64}$.

\section{A distinção entre a verdadeira religião do rigor filosófico e a falsa religião politeísta das superstições}

Esta distinção entre a afirmação da verdade óbvia da existência de Deus e as questões obscuras e incertas acerca da sua natureza e dos seus atributos, que Pânfilo introduz nos Diálogos, apresenta-se de forma recorrente na obra da História Natural da Religião, sob a forma da necessidade em explicar a origem da religião e de distinguir a verdadeira religião do rigor filosófico da falsa religião politeísta das superstições, que não tem origem na contemplação racional do Universo, mas sim nas paixões humanas. Nesta última obra,

\footnotetext{
59 Cf. ibidem, part. XII, p. 457.

60 Cf. ibidem, part. II, p. 398.

61 Cf. ibidem, part. III, p. 404.

62 Cf. ibidem, part. II, p. 391.

63 Cf. ibidem, part. III, p. 404.

64 Cf. ibidem, part. IV, p. 408.
} 
após a distinção inicial entre os dois teísmos, o autor procura identificar os princípios e causas que deram origem às religiões politeístas primitivas. Tal como descreve na segunda secção, o medo sentido perante os males do mundo do sofrimento, da injustiça e da morte, bem como a esperança de os superar, são uma primeira justificação ${ }^{65}$. Explica David Hume que as primeiras ideias religiosas dos idólatras não surgiram da análise racional das operações da natureza, a qual conduziria à conceção monoteísta de um único ser divino que conferiu existência e ordem à vasta máquina do Universo, ajustando as suas partes segundo um plano regular ${ }^{66}$, mas surgiram dos medos e esperanças que animam as mentes. Esses deuses, que tutelam cada nação e que são concebidos, não pelo puro amor à verdade, mas pelas afeições comuns da vida na preocupação pela felicidade e no terror pela miséria futura da condenação eterna, têm uma ação que não é certa e invariável: são fonte da boa ou má fortuna na governação de cada acontecimento natural e de cada ação humana de acordo com a boa ou má celebração dos sacrifícios, ritos e cerimónias $^{67}$.

Uma segunda explicação é a tendência humana para tudo conceber à sua imagem, elemento comum ao politeísmo grego, ao monoteísmo judaico-cristão e islâmico e à religião natural, que concebe o Arquiteto divino semelhante ao homem, embora dotado de poderes infinitos. Como descreve na terceira secção, não só as partes inanimadas da natureza são personificadas e adquirem sentimentos e paixões, levando a considerar que cada campo ou bosque possui um poder invisível que o habita e protege, como também a própria Divindade é caracterizada com as paixões e fraquezas humanas da inveja, da vingança e do capricho ${ }^{68}$.

Como descreve nos Diálogos pela voz de Demea contra as ideias justas e adequadas da natureza divina apresentadas por Cleanto, embora não vá ao ponto de partilhar com Plotino a noção de que a verdadeira adoração da realidade divina consiste na misteriosa autoaniquilação ou total extinção das nossas faculdades, D. Hume considera despropositado apresentar a Divindade como algo completamente compreensível e similar à mente humana e transferir para o Ser supremo os sentimentos humanos da gratidão e do ressentimento, do amor e da inveja, da amizade e da rivalidade. Explicando que todas estas ideias derivadas dos sentidos são ilusórias, considera que não podem pertencer a uma Inteligência Suprema ${ }^{69}$, apresentando a sua natureza

${ }^{65}$ Cf. idem, Natural History of Religion, sect. II, in The Philosophical Works, volume 4, pp. 315-316.

66 Cf. ibidem, sect. II, p. 314.

67 Cf. ibidem, sect. II, p. 315.

68 Cf. ibidem, sect. III, p. 317.

69 Cf. idem, Dialogues Concerning Natural Religion, part. III, in The Philosophical 
como uma realidade misteriosa, incompatível com as posições antropomórficas $^{70}$.

Como vimos anteriormente, a estas perspetivas do teísmo supersticioso, David Hume, na secção VI da História Natural da Religião, opõe as posições do teísmo mais zeloso e refinado, identificado por nós com a perspetiva deísta, que negando a providência particular e a conceção pessoal de Deus, afirma que a mente soberana ou primeiro princípio, depois de fixar as leis gerais da natureza, permite que atuem de forma livre e ininterrupta, não perturbando a ordem dos acontecimentos através de volições particulares ${ }^{71}$. Podemos dizer que a posição de David Hume, na rejeição da total similaridade entre a Divindade e a mente humana, se situa no plano intermédio entre as posições limite dos místicos, que defendem a absoluta incompreensibilidade de Deus e a dos céticos ateus, que afirmam que a causa de todas as coisas é absolutamente desconhecida e ininteligível ${ }^{72}$. Embora afirme que a imagem da divindade está desfigurada pelas religiões populares, defendendo uma certa similitude entre a idolatria e o ateísmo ${ }^{73}$, o autor considera que a propensão universal para acreditar num ser supremo invisível e inteligente é «uma espécie de marca ou sinal que o artífice divino colocou na obra, e seguramente nada pode dignificar mais os seres humanos do que terem sido escolhidos para este efeito entre todas as outras partes da criação» ${ }^{74}$.

\section{A recusa de Deus imanente na ordem natural do mundo material como alternativa ao antropomorfismo}

A alternativa a este antropomorfismo é apresentada na obra dos Diálogos, através de Filon, pela defesa de que o princípio da ordem natural é eterno e imanente ao mundo ${ }^{75}$, argumentando que pelo facto de o Universo se apresentar mais semelhante aos corpos animais e vegetais do que às obras de arte humana é mais provável que a sua causa e origem se assemelhe mais à

Works, volume 2, p. 404.

70 Cf. ibidem, part. IV, pp. 405-406.

71 Cf. idem, Natural History of Religion, sect. VI, in The Philosophical Works, volume 4, p. 329.

72 Cf. idem, Dialogues Concerning Natural Religion, part. IV, in The Philosophical Works, volume 2, p. 405.

73 Cf. ibidem, part. IV, p. 407.

74 «(...) may be considered as a kind of mark or stamp, which the divine workman has set upon his work; and nothing surely can more dignify mankind, than to be thus selected from all other parts of the creation (...)»: idem, Natural History of Religion, sect. $\mathrm{XV}$, in The Philosophical Works, volume 4, p. 362.

75 Cf. idem, Dialogues Concerning Natural Religion, part. VI, in The Philosophical Works Diálogos, volume 2, p. 419. 
geração ou vegetação do que à razão ou ao desígnio ${ }^{76}$. Esta posição defende a ordem e a adaptação na natureza, como as únicas provas irrefutáveis e $a$ posteriori da existência de Deus (contra as provas a priori da religião revelada), descrevendo os vários inconvenientes do antropomorfismo e recusando a existência de um plano do mundo formado na mente divina ${ }^{77}$. Assim, contra Cleanto, que infere um autor inteligente do mundo, a partir da ordem e harmonia natural ${ }^{78}$, Filon afirma nesta secção que o mundo material contém no seu interior o princípio da sua ordem e é nesse dinamismo que se encontra o verdadeiro Deus, não sendo necessário continuar in infinitum para além da realidade da Natureza ${ }^{79}$.

No seu diálogo com o teísta Cleanto, o cético Filon considera que a perspetiva antropomorfista que levantaria menos problemas seria a adotada pelos teístas da antiguidade a partir da noção da unidade indissociável entre mente e corpo. Descrevendo que o Universo se apresenta ao nosso conhecimento como semelhante a um animal ou corpo organizado, Filon sugere a hipótese de considerar o Universo como uma realidade animada por um princípio semelhante de vida e movimento. Esse princípio que o anima seria a Divindade, que assim se constituiria como a Alma do mundo ${ }^{80}$.

Assemelhando-se mais a um corpo humano do que a um engenho ou artefacto humano, faria sentido caracterizar o mundo como o corpo de Deus, apresentando-se esta teoria com a vantagem de conceber a mente divina, não apenas como uma mera substância espiritual, mas como uma ordem inseparável do corpo na realidade sensível da sua atividade natural ${ }^{81}$. Só a consideração de um princípio imanente à realidade dinâmica do mundo, nesta ou noutra teoria semelhante, poderia resolver as dificuldades inerentes à prova experimental ou a posteriori da existência da Divindade e da causa das leis invioláveis que governam a natureza, onde o acaso não tem lugar ${ }^{82}$.

Mas na obra História Natural da Religião, e à semelhança do defendido por Cleanto nos Diálogos, David Hume admite o carácter inteligente desse Ser perfeito que ordenou o Universo e toda a estrutura operacional da natureza $^{83}$ com uma intenção e um desígnio ${ }^{84}$, embora recuse a configuração

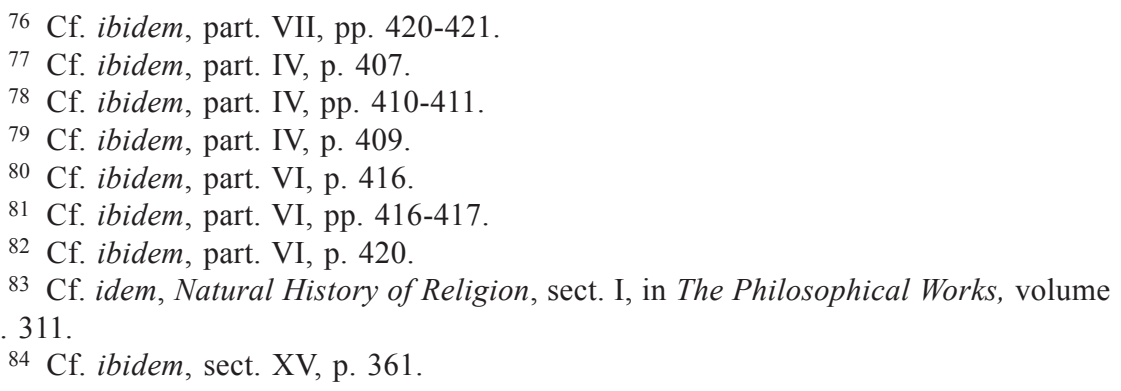


mítica da realidade, em que cada acontecimento natural ou qualquer paixão aparecem governados de forma imediata e direta pelas volições particulares de um agente inteligente ou de um deus, no sentido em que nada pode ocorrer de próspero ou adverso que não seja pela coadjuvância de preces e orações ${ }^{85}$. Por isso, recusa a existência de diversos poderes invisíveis que se misturam na ordem humana com os atributos de pensamento, razão, paixão e também formas humanas ${ }^{86}$.

Nesta obra, David Hume, raciocinando através de argumentos a partir da conceção dos objetos naturais ${ }^{87}$, admite que há um poder invisível e inteligente no mundo ${ }^{88}$ e opondo a noção politeísta e mitologista de geração à noção monoteísta de criação $^{89}$, supõe que o mundo é obra desse ser divino, causa original de toda a realidade ${ }^{90}$. E em contraposição com o defendido por Filon que aponta a geração e a vegetação como a origem dos seres naturais, assim o reafirma na secção XV da História Natural da Religião, realçando que a organização do mundo emerge da razão divina e do desígnio:

Em todas as coisas é evidente um propósito, uma intenção, um desígnio, e, quando a nossa compreensão se alarga ao ponto de contemplar a primeira origem deste sistema visível, temos de adotar a ideia de uma causa ou autor inteligente com a mais forte convicção. Também as máximas uniformes que prevalecem ao longo de toda a estrutura do Universo levam-nos naturalmente, ou mesmo necessariamente, a conceber esta inteligência como única e indivisa, quando os preconceitos da educação não se opõem a uma teoria tão razoável. ${ }^{91}$

No entanto, apesar da diferença de perspetivas entre os diferentes autores dos Diálogos, há uma questão essencial que é comum a todos, como é comum às diversas obras em que o autor apresenta a sua filosofia da religião, a qual se torna explícita através da voz do próprio Filon na segunda parte dos Diálogos, admitindo com Demea que o que está em causa não é a existência de Deus, mas sim, por um lado, a caracterização dos seus atribu-

\footnotetext{
85 Cf. ibidem, sect. II, p. 315; sect. V, p. 326.

86 Cf. ibidem, sect. III, p. 318 .

87 Cf. ibidem, sect. V, p. 325.

88 Cf. ibidem, sect. IV, p. 320.

89 Cf. ibidem, sect. IV, p. 322.

90 Cf. ibidem, sect. V, p. 325.
}

91 «A purpose, an intention, a design is evident in every thing; and when our comprehension is so far enlarged as to contemplate the first rise of this visible system, we must adopt, with the strongest conviction, the idea of some intelligent cause or author. The uniform maxims too, which prevail throughout the whole frame of the universe, naturally, if not necessarily, leads us to conceive this intelligence as single and undivided, where the prejudices of education oppose not so reasonable a theory.» Ibidem, sect. XV, pp. 361. 
tos, que não podem ser compreendidos pela razão humana e, por outro lado, a caracterização das suas perfeições, que não têm analogia ou semelhança com as perfeições de uma criatura humana. As nossas ideias não correspondem à natureza divina, porque Deus é infinitamente superior à nossa visão e compreensão limitadas ${ }^{92}$. Tal como descreve logo no início dos Diálogos, se a existência de Deus surge como uma verdade óbvia, o mesmo já não se passa com as questões obscuras sobre a natureza, os atributos, os decretos e a providência desse ser divino, onde se instala a dúvida, a incerteza e a contradição ${ }^{93}$.

Esta questão é sublinhada na segunda parte dos Diálogos, quando Filon se dirige a Demea para falar da distinção entre verdade fundamental, certa e óbvia da existência de Deus e o carácter obscuro da sua natureza:

E é certo que quando os homens razoáveis discutem estes assuntos a questão nunca pode ser relativa à existência, mas apenas à natureza da Divindade. A primeira verdade, como bem observaste, é inquestionável e auto-evidente. Nada existe sem uma causa, e à causa original deste universo (seja ela qual for) chamamos Deus e piedosamente atribuímos-lhe todas as espécies de perfeições. (...) Mas como toda a perfeição é inteiramente relativa, nunca devemos imaginar que compreendemos os atributos deste ser divino ou supor que as suas perfeições têm alguma analogia ou semelhança com as perfeições de uma criatura humana. ${ }^{94}$

\section{Conclusão: David Hume defende a perspetiva deísta da existência de um Ser supremo criador, mas não redentor do mundo.}

Pela análise das diferentes obras de David Hume, podemos concluir que, ao contrário daquilo que normalmente tem sido interpretado, apenas é possível encontrar total identificação entre o seu pensamento e o de Filon, nas críticas ao antropomorfismo e à noção de estado perfeito e escatológico da vida futura, pela recusa de atribuir a Deus a benevolência e a misericór-

92 Cf. idem, Dialogues Concerning Natural Religion, part. II, in The Philosophical Works, volume 2, p. 391.

93 Cf. ibidem, Pamphilus to Hermippus, p. 5.

94 «But surely, where reasonable men treat these subjects, the question can never be concerning the Being, but only the Nature of the Deity. The former truth, as you well observe, is unquestionable and self-evident. Nothing exists without a cause; and the original cause of this universe (whatever it be) we call God; and piously ascribe to him every species of perfection. (...) But as all perfection is entirely relative, we ought never to imagine, that we comprehend the attributes of this divine Being, or to suppose, that his perfections have any analogy or likeness to the perfections of a human creature»: ibidem, part. II, p. 391. 
dia como realidades da mesma natureza das virtudes existentes nas criaturas humanas ${ }^{95}$.

Por outro lado, ao contrário daquilo que também tem sido apresentado, encontramos uma certa identificação entre o seu pensamento e o de Cleanto, no que se refere, por exemplo, à defesa que este faz da noção de desígnio e finalidade da natureza ${ }^{96}$, e encontramos uma certa identificação com o pensamento de Demea, no que se refere, por exemplo, à atribuição de uma causa e razão para a existência dos seres ${ }^{97}$. Para David Hume não está em causa a existência de um Ser supremo criador do Universo natural e das leis que o regem.

Mas não podemos terminar sem deixar uma pergunta, que é reflexo do próprio percurso indeciso e sinuoso da filosofia da religião do autor: onde está a inteligência e a Glória de um Deus de quem só se podem demonstrar os atributos naturais e a quem é incerta a atribuição dos atributos morais? Onde está o desígnio de um Universo que não pode ter na redenção integral do corpo e da alma o seu Fim?

\section{Fontes}

Hume, David, An Enquiry Concerning Human Understanding, sect. II, n. ${ }^{\circ} 14$, in Enquiries Concerning Human Understanding and Concerning the Principles of Morals, edited with introduction, comparative table of contents, and analytical índex by L. A. Selby-Bigge, third edition with text revised and notes by P.H. Nidditch, London, Oxford University Press, 1982.

Hume, David, Dialogues Concerning Natural Religion, part. XI, in The Philosophical Works, edited by Thomas Hill Green and Thomas Hodge Grose, volume 2, London, Scientia Verlag Aalen, 1964.

Hume, David, Natural History of Religion, sect. II, in The Philosophical Works, edited by Thomas Hill Green and Thomas Hodge Grose, volume 4, London, Scientia Verlag Aalen, 1964.

Hume, David, Unpublished Essays, essay I, in The Philosophical Works, edited by Thomas Hill Green and Thomas Hodge Grose, volume 4, London, Scientia Verlag Aalen, 1964.

\footnotetext{
95 Cf. ibidem, part. X, p. 440.

96 Cf. loc. cit.

97 Cf. ibidem, part. IX, p. 431.
} 


\section{Bibliografia secundária}

Chirpaz, François, Hume et le procès de la mètaphysique, Paris, Editions Beauchesne, 1989.

Cléro, Jean-Pierre, Hume: une philosophie des Contraditions, Paris, Libraire Philosophique J. Vrin, 1998.

Davies, Brian, An Introduction to the Philosophy of Religion, Oxford, Oxford University Press, 2003.

Gaskin, J.C.A., Hume's Philosophy of Religion, London, Macmillan, 1988.

Kant, Immanuel, Kritik der reinen Vernunft, Hamburg, Verlag Von Félix Meiner, 1952, = [Crítica da Razão Pura, trad. de Manuela Pinto dos Santos e Alexandre Fradique Morujão, Lisboa, Fundação Calouste Gulbenkian, 1989].

Leroy, Andre Louis, La Critique et la Religion chez David Hume, Paris, 1930.

Monteiro, João Paulo, «Introdução», in Obras sobre Religião, Lisboa, Fundação Calouste Gulbenkian, 2005.

Monteiro, João Paulo, Hume e a Epistemologia, Lisboa, INCM, 1984.

Monteiro, João Paulo, Natureza, Conhecimento e Moral na Filosofia de Hume, São Paulo, 1975.

Monteiro, João Paulo, Novos Estudos Humeanos, Lisboa, INCM, 2003.

Norman Kemp, The Philosophy of David Hume, London, Macmillan, 1941.

Norton, David Fate (org.), The Cambridge Companion to Hume, Cambridge, Cambridge Universtity Press, 1998.

Noxon, James, Hume's Philosophical Development, Oxford, Oxford University Press, 1973.

Nunes, Álvaro, «Introdução», in Diálogos Sobre a Religião Natural, Lisboa, Edições 70, 2005.

O’Connor, David, Routledge Philosophy Guidebook to Hume on Religion, London, Routledge, 2001.

Shanks, Niall, God, the Devil and Darwin: A Critique of Intelligent Design Theory, Oxford, Oxford University Press, 2004.

Strawson, Galen, The Secret Connexion: Causation, Realism and David Hume, Oxford, Clarendon Ptress, 2003. 